\title{
Ventilation system of Railway, modified to versatile one - Turbo ventilation
}

\author{
Ankit Kalyan Kharde $\#^{*}$ \\ \#Department of Mechanical Engg, Marathwada Mitra Mandala's College of Engineering, Savitribai Phule Pune University, Pune, India
}

Accepted 02 March 2016, Available online 15 March 2016, Special Issue-4 (March 2016)

\begin{abstract}
The act of supplying fresh air and getting rid of foul air is ventilation. A mechanical system that provides fresh air is ventilation system. It is very useful in controlling indoor air quality. Many Indians travel by railway daily. Most of the Indian Railways are provided with natural ventilation by windows and doors. If all windows and doors are closed or the crowd is more, this type of ventilation system fail to provide effective ventilation. This creates suffocation. Also, smoke, dust, foul smell, etc. once trapped, it becomes very difficult to throw it out. Thus, there is a need of alternate ventilation. 'Turbo Ventilation' is a solution for this. Turbo Ventilation includes a passage for natural wind to pass through a unit which in turn produces electricity and then air is further sent to passengers in railway coach. This system not only provides proper ventilation, but also works as exhaust system whenever required. This has many advantages over the present ventilation system with some limitations and that too at reasonable cost.
\end{abstract}

Keywords: Ventilation, natural wind.

\section{Introduction}

Ventilation: The act of supplying fresh air and getting rid of foul air is ventilation, also called as airing. This is mainly used to control indoor air quality. A mechanical system that provides fresh air is called ventilation system.

\subsection{Types of ventilation}

a. Mechanical ventilation- System that uses mechanical means, like fan for intake of air.

b. Natural ventilation- Designed passive methods for intake of air without using mechanical system.

c. Hybrid ventilation- Systems using both, mechanical and natural ventilation.

\subsection{Importance of ventilation}

A) It can help reduce condensation.

B) Concentration of volatile organic compounds can be decreased.

C) Allergens (pollen, dust, etc) can be filtered out.

D) Helps protecting respiratory health.

E) Reduces back drafting risks, etc.

Blowers, fans, exhausts, etc. are used in many places for proper ventilation, but generally at the public

*Corresponding author: Ankit Kalyan Kharde places like public buses, railway station, etc. natural ventilation is used.

\section{Present Railway ventilation}

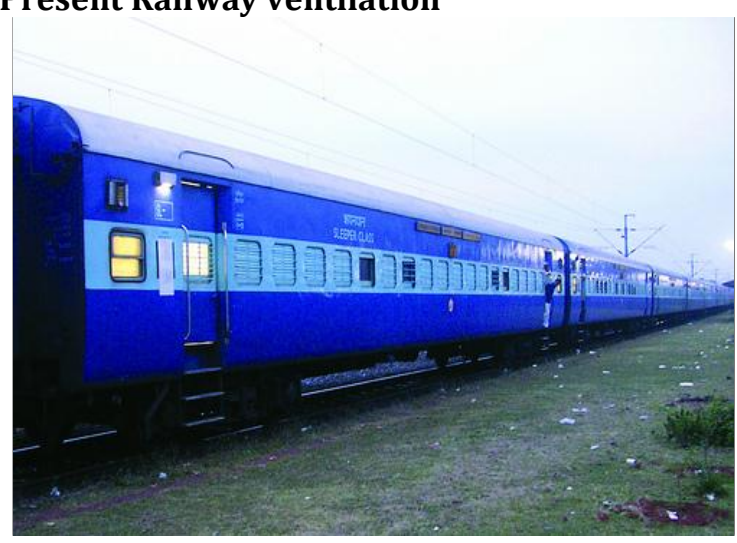

Figure 1: Present railway image

Indian railway coaches have always been dependent on their windows and doors for natural ventilation, but during winter season, due to cold atmosphere, it is not comfortable to keep windows and doors open. Even in rainy season, it can not be kept open. In hot weather, keeping windows open is a feasible option but the open windows at high speed invite in lots of dust and also enable theft of passenger's belongings.

The latest adapted ventilation system in Indian Railway includes combined system of evaporation cooling and forced air flow by wind catching devices installed on roof (Saloon HVAC system). 
This is a clean and hygienic method, but doing some modification will not only make it more efficient but also will suffice certain other objectives.

Many people in India travel by railway, Daily. Windows provide good ventilation, but in case of sleeper coach or if crowd is excess, windows fail to provide effective ventilation. This creates suffocation. Also, smoke, dust or other pollutants once trapped, are very difficult to throw out.

\section{Modified Ventilation system}

\subsection{Construction}
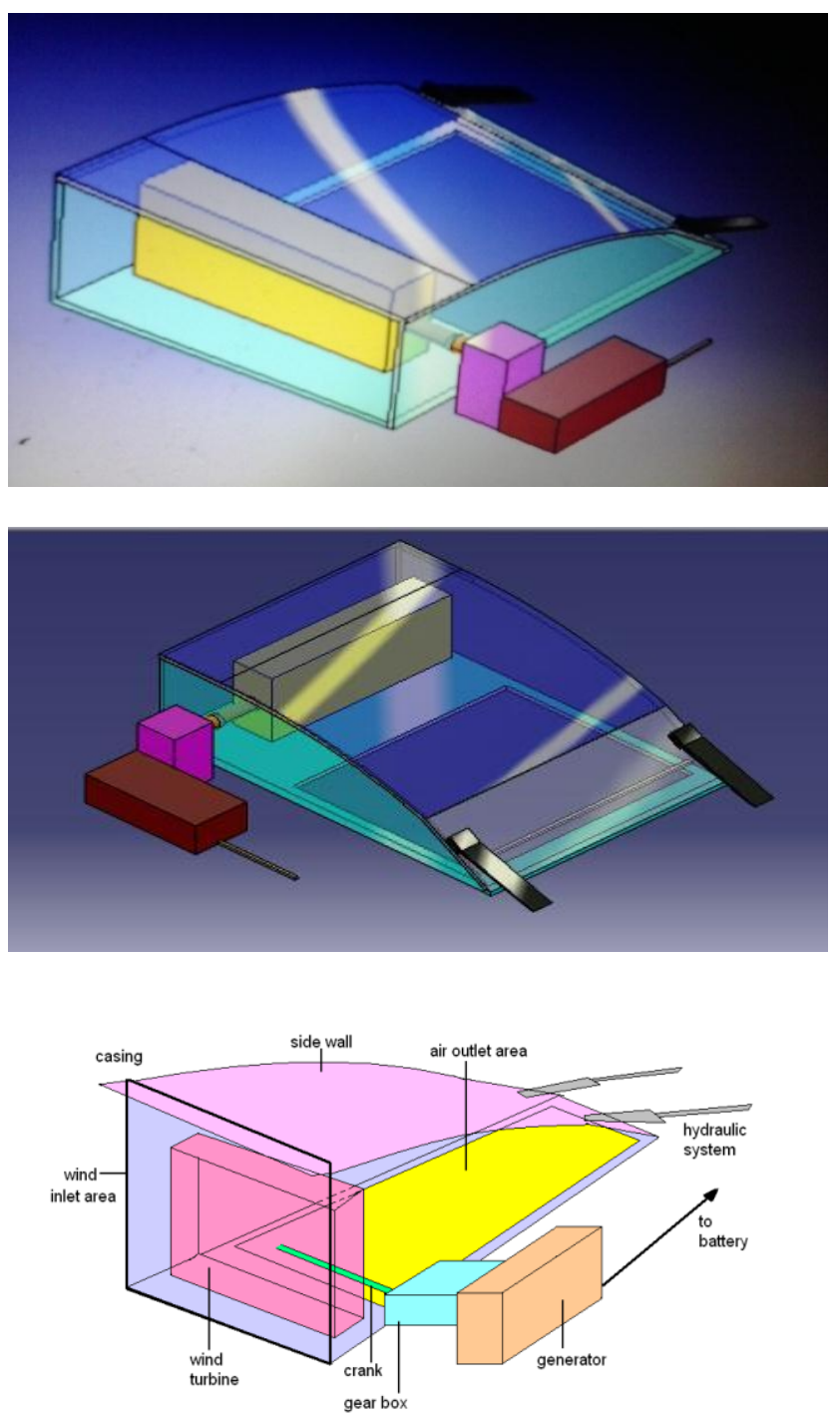

Figure 2: Isometric views of turbo ventilation unit

- Casing- It is covering of the unit and serves two purposes: protection of internal parts and ease in air flow due to aerodynamic shape. It must be rigid.

- Wind inlet area- It is the space through which air will enter the unit. It is designed so as to supply maximum wind inside the unit.

- Turbine- The wind that is entered from Wind inlet area will have to pass through small sized wind turbine placed in casing. It will be with horizontal axis, perpendicular to air flow so as to get the generator outside the casing. Even vertical axis will work to get generator above casing.

- Generator- The output crank shaft of wind turbine with appropriate gear ratio will be connected to generator, placed outside casing. It will be completely covered for its protection and safe use.

- $\quad$ Side wall- It consist of rearmost side and some top part of casing. It is provided with hinges and hydraulic system, which will help for its opening and closing purpose.

- Baffles- Baffles will be provided in the path of air, after passing through wind turbine. This will ease in flow of wind.

- Shutter- It is a metallic plate placed before wind inlet area to limit the flow of wind inside the unit.

- $\quad$ Air outlet area

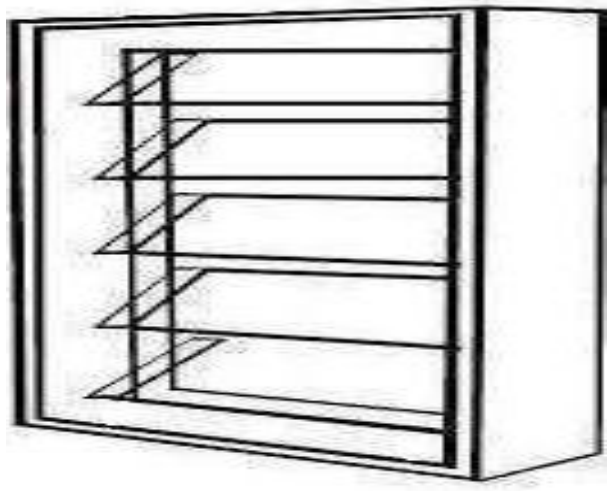

Figure 3: Louver window

This is the area on roof of coach with louver windows which will provide a path for air to flow out of the unit.

- Air filter- These can be provided at appropriate location to supply filtered air for passengers.

\subsection{Working}

3.2.1 Working principle - When a locomotive is advancing, the natural flow of air provides a lot of resisting force for its advancement.

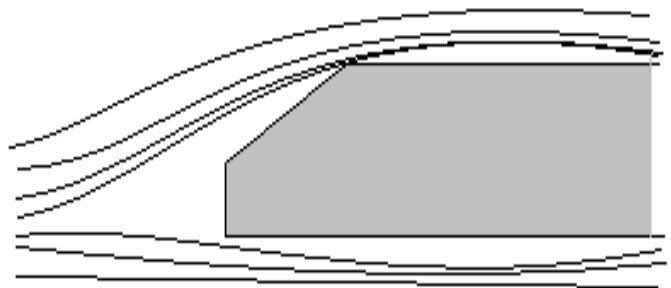

Figure 4: Wind flow over railway 


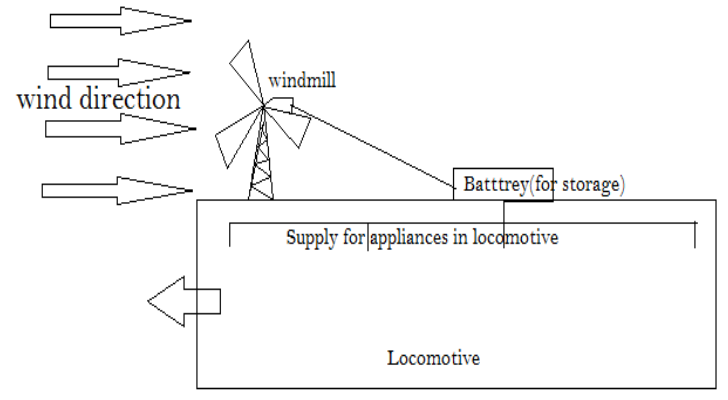

Figure 5: Working mechanism for wind turbine

\subsubsection{Working linkage mechanism}

When the louver windows are in position that makes complete air flow inside coach, side-wall will be closed i.e. all air inside the unit will be made to flow in coach (refer figure 6). Also the shutter will be horizontally rested on ground which will not restrict the flow of air inside unit.

There will be relative motion between louver window, shutter and side-wall for proper air flow. For every angular movement of louver window, there will be corresponding angular movement of side-wall and shutter as shown in figure 6.

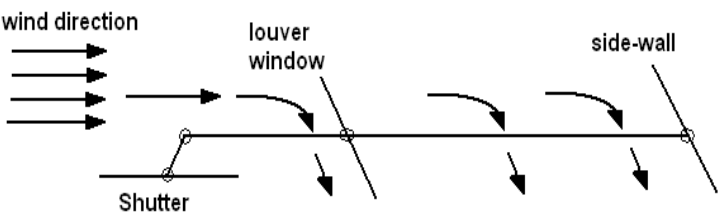

(a)

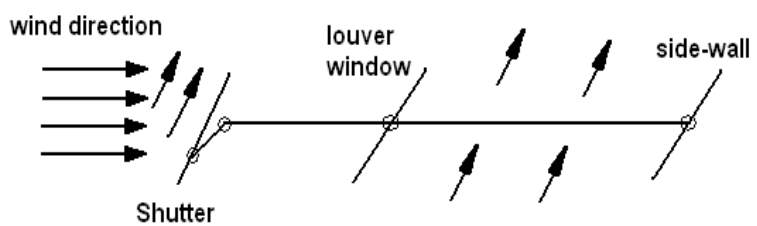

(b)

Figure 6: Linkages working mechanism

Thus, by changing the position of louver window, we can control air inlet inside the coach.This will provide an option for the passengers to control the air flowing inside coach.

\subsubsection{The unit will work in two cases}

\section{CASE I- Air supply for passengers}

When the wind flows through 'Wind inlet area', it will be passed through small sized wind turbine (refer figure 7) placed in its path.

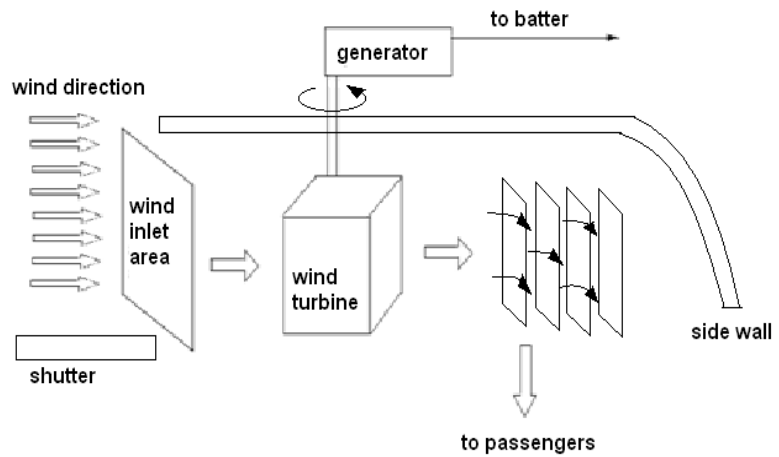

Figure 7: Block diagram for case I

This will make the blades of turbine move and thus rotate the crankshaft. This crankshaft is further attached to gear assembly for appropriate gear ratio and then to generator that will in turn produce electricity. Passing wind through wind turbine will decrease its speed.

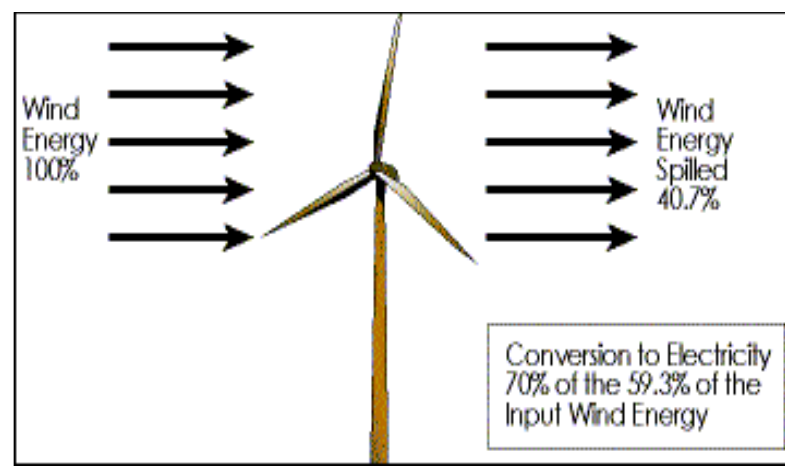

Figure 8: Wind energy basics

Considering average speed of railway as $60 \mathrm{Km} / \mathrm{h}$, wind flow will also be the same. Thus, we get 22.42 $\mathrm{Km} / \mathrm{h}$ speed of air after passing it through turbine.

This reduced velocity air will be then passed further part of the unit, from where It will be sent to coach via. 'Air outlet area'. The air given inside coach will be distributed in nearby region.

The louver windows provided here, baffles and design of casing in this part will make it easy to flow in railway coach. (As shown in figure 6)

These louver windows can be moved accordingly to get appropriate amount of air for passengers.

Hence, we achieve easy flow of air inside the coach. The outward flow or exhaust of air will be done as discussed in case-II.

\section{CASE II- Exhaust System}

For exhaust, (refer figure 6 and 9) louver window will be tilted by $90^{\circ}$ from their position in case I and accordingly, side-wall will be opened completely and shutter will be tilted to close the air inlet This will stop the intake of air inside coach. 


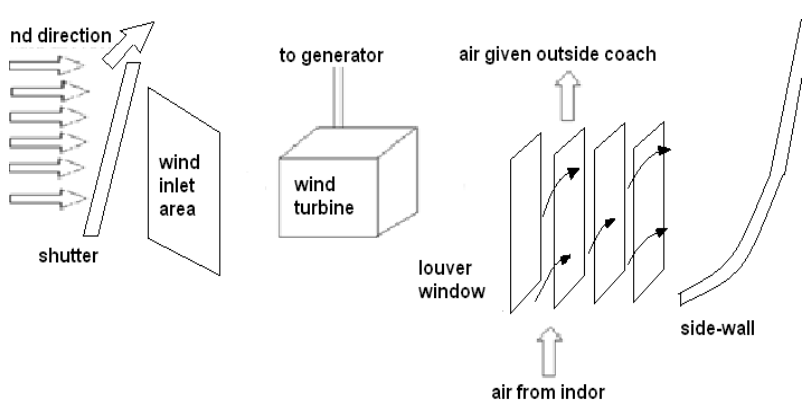

Figure 9: Block diagram for case II

Thus, no air flow will take place from wind inlet area to louver windows. Rather, air present in the indoors of coach will be drawn outside as, at the same time other units will continuously force outside air to flow in indoors. In this way, air circulation takes place as shown.

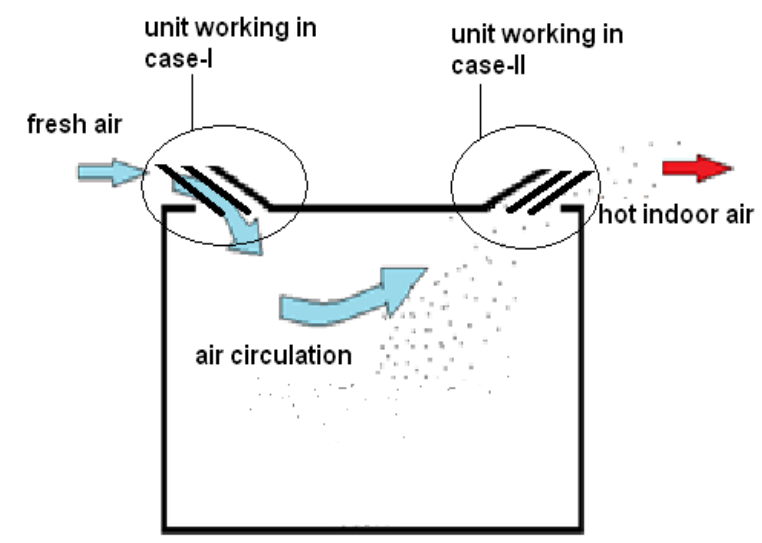

Figure 10: Forcing internal undesired air to flow out

The part of coach where we require exhaust, the unit will work as case-II, whereas other units will work same as case-I.

In the inner part of coach, adjoining the unit placed on roof, a smoke sensor will be attached, which on sensing smoke will change the direction of louver window by $90^{\circ}$.

The case-II will be used in emergency cases like. electric accidents, fire, etc. It can be even done manually in case of suffocation using a switch provided for passengers.

There is a chance that the exhaust air by one unit can be taken as inlet air by another. Side-wall will avoid this, as it is open, it will push exhaust undesirable air outside at certain height. So, this air will not come in contact with 'Air inlet area' of other units.

To avoid rain water enter inside coach, the base area will be given slope which will make rain water drain outside the unit on the roof of coach.

Critical case- If all the sensors in a coach blow on, the unit placed in center will be in initial position, so as to take intake air and others will be in reversed direction, automatically.

\subsection{Specifications}

Placing or arrangement of units

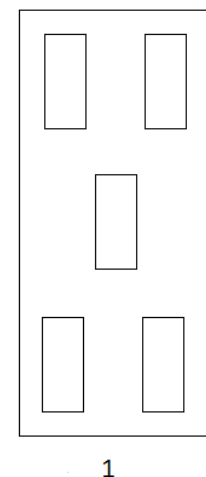

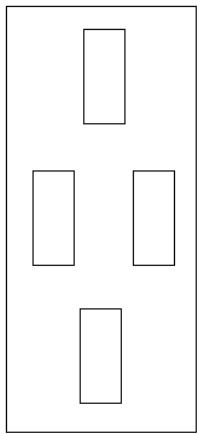

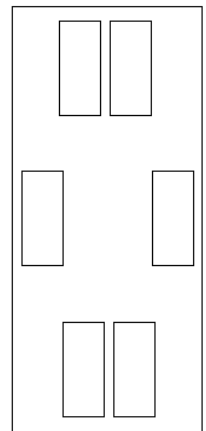

3
Top view of Railway coach

Figure 11: Units on roof of railway

There will be number of ways by which we can mount different units on the roof of railway coach. Some of which are shown in figure 11.

- Windmill
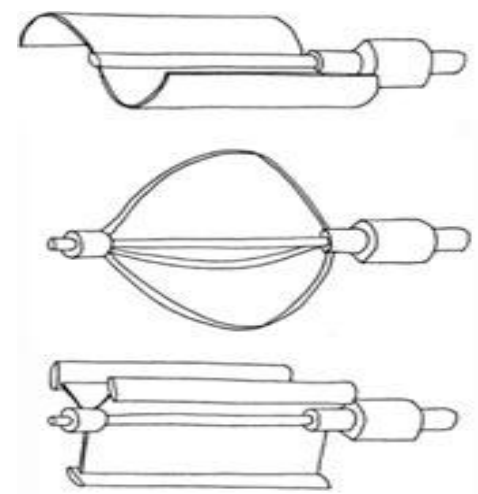

Figure 12: Windmills

A windmill of small size and horizontal axis is desired since it will result the crankshaft outside the casing.

Sensor

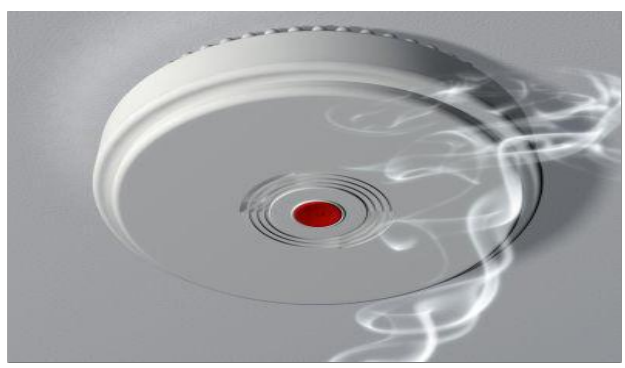

Figure 13: Smoke sensor

These smoke sensors will work in case of fire accidents i.e. optical smoke sensor. It will give signal to the hydraulic system attached to side-wall. 
- Power switch

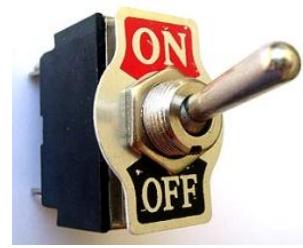

Figure 14: Switch

In case sensors do not work, power switch will be provided to passengers. Pressing this, units will be switched to exhaust mode. It can also be used when passengers wants exhaust. The same will work to bring system in normal mode.

- Louver and side-wall relative motion mechanism:

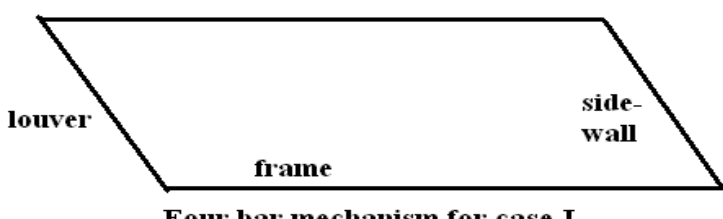

Four bar mechanism for case-I

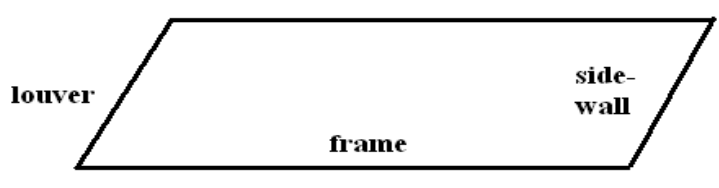

Four bar mechanism for case-II

Figure 15: Four bar mechanism

A simple Four bar mechanism can be used to achieve the relative motion between louver and side-wall. (Explained in detail in figure 6)

\section{Significant points achieved}

A) Proper ventilation

B) Effective exhaust system

C) Power generation:

Kinetic energy $=1 / 2 * \mathrm{M}^{*} \mathrm{~V}^{2}$

Power $=($ Kinetic energy $) *$ (velocity)

$=\left(\mathrm{MV}^{2} * \mathrm{~V}\right) / 2$

$=\mathrm{MV}^{3} / 2$

For average atmospheric conditions of density and moisture content,

Power per meter square $=.0006^{*} \mathrm{v}^{3}$

If we assume that a railway has its average speed of 60 kmph, we get $\mathrm{v}=60 \mathrm{kmph} \quad=17 \mathrm{~m} / \mathrm{s}$

Thus by the equation no. 1 we get power $=291.6 \mathrm{~W}$ for one hour.

... (Considering size of windmill as $54 \mathrm{~cm} \mathrm{x} 24 \mathrm{~cm}$ )

For one hour journey, we get $60 \mathrm{kmph}$ for average 45 minutes.

Thus, the power produced by one unit for one hour journey $=(291.6 * 45) / 60 \quad=218.7 \mathrm{~W}$

This is power generated by one unit. It will be multiplied by the number of units mounted on roof of the locomotive.

The power generated by windmills depends mainly on its shape, size, wind velocity, etc.

1. Appropriate shape shall be chosen according to constrains.

2. There is a size limitation, as increase in size will increase the resistance to locomotive advancement. Keeping the windmill size small and thus size of unit small, is always recommended. The size must be decided according to air required in indoors.

3. There is speed limit for the turbines. The optimum speed of wind in which a turbine works effectively is to be considered. If the locomotive goes above maximum permissible velocity, the shutters provided will be actuated so as to reduce inlet air flow to reduce impact of wind on turbine.

\section{Comparison}

Table 1: Comparison

\begin{tabular}{|c|c|c|}
\hline $\begin{array}{c}\text { Sr. } \\
\text { No. }\end{array}$ & $\begin{array}{c}\text { Present ventilation } \\
\text { system }\end{array}$ & Turbo Ventilation \\
\hline 1. & Difficult for exhaust & $\begin{array}{c}\text { Easy and effective } \\
\text { ventilation system }\end{array}$ \\
\hline $\mathbf{2 .}$ & No power generation & $\begin{array}{c}\text { Power generation takes } \\
\text { place }\end{array}$ \\
\hline $\mathbf{3 .}$ & No air filters & $\begin{array}{c}\text { Air filters can be } \\
\text { provided }\end{array}$ \\
\hline $\mathbf{4 .}$ & $\begin{array}{c}\text { Provides only } \\
\text { ventilation }\end{array}$ & $\begin{array}{c}\text { Provides ventilation } \\
\text { along with safety and } \\
\text { power generation }\end{array}$ \\
\hline
\end{tabular}

\section{Advantages}

a) Effective natural ventilation

b) Effective exhaust

c) Power generation

d) Air filters will provide filtered fresh air

e) Reasonable cost

\section{Limitations}

a) The unit on roof may create resistance to railway advancement(Aerodynamic shape can overcome this limitation)

b) Storage and supply of generated power is required periodically 
c) According to height of unit, some changes in path of railway has to be done e.g. Tunnel

d) Regular maintenance is required

\section{Conclusion}

'Turbo ventilation' is indeed a versatile ventilation system. It is difficult to get replaced over air conditioning systems as it does not provide cool air, but it is definitely a good alternative for Indian locals and express trains which depend on windows and doors for their ventilation. It has many areas to be worked on like shape, size, linkages provided, etc.

\section{References}

S. Rao and Dr. B.B. Parulekar, Engineering TechnologyNonconventional, renewable \& Conventional, Khanna Publishers, Third Edition, Seventh reprint: 2009, pp 305356

http://www.indianrailways.gov.in/IR\%20eBook/index.html https://en.wikipedia.org/wiki/Wind_turbine_design www.quora.com

http://www.smarterhomes.org.nz/energy/cooling/ http://www.level.org.nz/energy/renewable-electricitygeneration/wind-turbine-systems/ http://www.windenergy.org.nz/wind-energy https://www.wind-watch.org/faq-output.php http://www.railway-technology.com/projects 